STFM

SOCIETY OF TEACHERS OF From the Society of Teachers

FAMILY MEDICINE of Family Medicine

Ann Fam Med 2018;16:182. https://doi.org/10.1370/afm.2219.

\section{STFM ENHANCES ITS LEADING CHANGE OFFERINGS}

Training future leaders is key to family medicine's growth. STFM launched the first Leading Change Task Force in 2013 to create online learning modules to develop leaders in all areas of family medicine. The second Leading Change Taskforce created the Leading Change Fellowship in 2015 to educate and empower family medicine faculty to lead change within their institutions, larger surrounding environments, and at the national level. The fellowship has graduated 32 fellows.

In 2018, STFM activities centered around leading change are undergoing the following changes and enhancements.

\section{Revamped Online Leading Change Course}

STFM has reorganized its online Leading Change Course into shorter, more engaging modules (usually 3 to 5 minutes long) with quizzes and video vignettes to increase content retention. Experts featured in the vignettes include Mark Loafman, $\mathrm{MD}, \mathrm{MPH}_{i}$ Grant Greenberg, MD, MHSA, MA, Amy Odom, DO ind John Bachman, MD.

The learning experience uses updated technologies so the course is accessible from mobile devices as well as desktop computers. The course can be taken with a specific change project in mind or it can be used as a tool to learn more about how change happens in an institution.

A new Leading Change Workbook contains handouts and brief assignments for individual participants to reflect on and apply what they learned. Group learning activities are embedded within the modules.

Learners who complete the course receive a certificate of participation. The Leading Change Course is free to faculty, residents, and students with an account on STFM.org. Membership in STFM is not required.

\section{New Leadership}

Grant Greenberg, MD, MHSA, MA has recently been named Leading Change Fellowship Chair. "The importance of developing leaders in family medicine who can facilitate and manage change is the quintessential skill for the future of our profession. In my role as department chair at Lehigh Valley Health Network, I am immersed in change management at all levels and
I have spent most of my career developing educational and leadership skills to facilitate successful change," said Dr Greenberg. "I've found that successful change involves consensus, organization, communication, collaboration, and trust in leadership."

\section{New Name}

Beginning with the 2019 class, The Leading Change Fellowship will be called the Leading Change Institute. "We felt that, due to complexity of the content that is geared toward mid to senior faculty, that new name was more representative of the program," said Dr Greenberg.

The Leading Change Institute educates and empowers family medicine faculty to lead transformational change within their institutions, larger surrounding environments, and at the national level. Throughout the fellowship year, teams interact with mentors and attend training sessions at STFM conferences and via video conference. Fellows participate as interprofessional dyads and will implement a practice change. "The dyad is unique to this fellowship and it is thought that leading change is not a solo responsibility/act and therefore the dyad structure is essential," said Dr Greenberg. The dyad format recognizes that leadership, especially leadership around change, must include a highly functioning team and the dyad is the first step in that process.

The 2019-2020 Institute will begin at the STFM Annual Spring Conference, with a mid-year meeting at the Conference on Practice Improvement, culminating with graduation at the following STFM Annual Spring Conference. The dyad teams will also present their projects to a national audience at the STFM Annual Spring Conference.

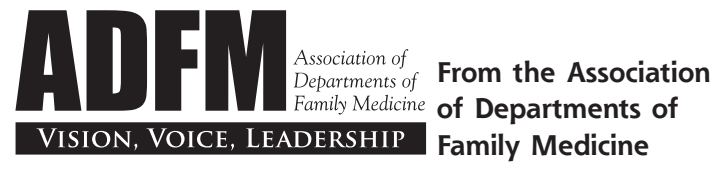

Ann Fam Med 2018;16:182-183. https://doi.org/10.1370/afm.2212.

\section{ADFM AND FMAHEALTH BOARDS' ENGAGEMENT AROUND A PUBLIC MEMBER PILOT STUDY}

Family Medicine for America's Health (FMAHealth. org) is a collaborative effort of 8 national family medicine organizations including the Association of Departments of Family Medicine (ADFM). FMAHealth has recommended that each sponsoring organization have a patient/public member on their board of directors. 
ADFM, in collaboration with FMAHealth, is conducting a 2-year pilot on the value of adding a public member to the ADFM Board of directors. The purpose of this pilot is to determine if the inclusion of a public member from outside of academic departments of family medicine will bring insights and a perspective that enhance the work of the Board in advancing the mission of ADFM. The public member will serve a 2-year term (February 2018-February 2020). ADFM will conduct an evaluation of the pilot program to inform a decision about whether to continue to include a public member position on the Board after the conclusion of the pilot phase in 2020 .

The Mission of ADFM is to transform care, education, and research to promote health equity and improve the health of the nation. Among our stated values is "Compassion: We commit to keeping the patient as the central focus." We see this pilot of including a public member perspective on our Board as closely aligned with this value and keeping the patient at the center of what we do. In referring to this position as a "public member," we also envision the role as contributing to all of ADFM's mission areas, which include research, education, and public service, in addition to patient care. The hypothesis to be tested is that an individual who is not from within our internal "family" of academic departments, but who appreciates our mission and is committed to the success of departments of family medicine, will bring complementary views and experiences that enhance the work of ADFM.

Even prior to FMAHealth's suggestion to add a patient/public member to the boards of our family medicine organizations, the American Board of Family Medicine (ABFM), the North American Primary Care Research Group (NAPCRG), and the American Academy of Family Physicians Foundation (AAFPF) had public members on their boards. They reported favorable experiences from broadening board membership. In fact, NAPCRG and the ABFM have increased the number of patient/public members to 2 and 3, respectively. FMAHealth, learning from their experience, has encouraged other family medicine organizations to expand their membership to include a patient/public member.

\section{Finding the "Right" Person}

In response to the encouragement by FMAHealth to include a patient/public member, the consensus of the ADFM Executive Committee was that it would be of value to ADFM to move in this direction on a pilot basis. Recognizing the desire for a patient/public member who can understand the broad mission of our academic constituent groups, we sought to recruit a public member with experience working in organizations, health systems, or larger academic entities (Table 1).

ADFM is very pleased to have received a number of applications from outstanding candidates. We are delighted to announce that Julie Moretz (Chief Experience Officer / Assistant Vice President, Patient- and Family-Centered Care, Center for Patients and Families, Augusta University Health System, Augusta, Georgia, https://jagwire.augusta.edu/archives/42306 ) will be serving in this unique pilot endeavor. We look forward to reporting the results of our evaluation of this pilot.

Kevin Grumbach, Val Gilchrist, Ardis Davis, Joseph Hobbs, Mack Wortbington, F. David Schneider, Glen Stream, Mal O'Connor, Tom Campbell 